\title{
Optimal Allocation and Size of Static VAr Compensator (SVC) for Voltage Stability Improvement in the National Grid of Sudan $500 \mathrm{KV}$ Transmission Lines
}

\author{
ALhbeeb Babaker ALhbeeb ${ }^{1}$, Adam Abdullah Adam², Mansour Babiker Idris ${ }^{3}$ \\ Faculty of Engineering, Kassala University, Sudan ${ }^{1,3}$ \\ Faculty of Khartoum Technology, Sudan ${ }^{2}$
}

\begin{abstract}
Static var compensator (SVC) as one component of flexible Ac transmission systems (FACTS) device. Play an important role in controlling reactive power flow to power network. Because of economic consideration identifying the best location for installing the SVC is also important. This paper discusses the optimal allocation and size of static var compensator to improve voltage magnitude for a power system. National grid of Sudan (NGS) transmission lines$500 \mathrm{KV}$ is used as case study. Solution is obtained using Neplan software. The results show the optimal allocation is in the kabashi bus with size of 90.392MVAR.
\end{abstract}

Keywords: Static var compensator (SVC), National grid of Sudan (NGS), flexible Ac transmission systems (FACTS) device.

\section{INTRODUCTION}

The concept of using solid-state power electronic converters for power flow control at transmission level has been known as FACTS. The idea has had some success in certain areas such as reactive power dispatch and control. However, the full use of FACTS for power flow control has had limited applications in part due to reliability concerns and in part due to availability of components. Perhaps the most salient consideration is the cost of these devices. A potential motivation for accelerated use of FACTS is the deregulation/ competitive environment in contemporary utility business. The potential ability of controlling the flow of electric power, and the ability to effectively join electric power networks that are not strongly interconnected, suggest that the FACTS may find new applications [2].

Power electronics based equipment, or FACTS, provide proven technical solutions to voltage stability problems. Especially, due to the increasing need for fast response for power quality and voltage stability. Static Var Compensators (SVC) has becom feasible Alternatives to a fixed reactive source, and therefore have received intensive interests [2].

\section{STATIC Var COMPENSATOR (SVC)}

The Static VAr Compensator (SVC) today is considered as a very mature technology. It has been used for reactive power compensation since the 1970s. A SVC is a shunt connected FACTS device whose output can be adjusted to exchange either capacitive or inductive currents to the connected system. This current is controlled to regulate specific parameters of the electrical power system (typically bus voltage) [3]. The thyristor has been an integral part in realizing the SVC and to enable control of its reactive power flow. It is used either as a switch or as a continuously controlled valve by controlling the firing angle. It should be noted that the SVC current will contain some harmonic content, something that needs attention design process [3].

\section{2-1Advantages of SVC}

The main advantages of SVCs over simple mechanically switched compensation schemes are their nearinstantaneous response to change in the system voltage. For this reason, they are often operate at close to their zero-point in order to maximize the reactive power correction. The of SVC use have the following profits [4]:

1. Improves system steady-state stability.

2. Improves system transient stability.

3. Better load division on parallel circuits

4. Reduces voltage drops in load areas during severe disturbances.

5. Reduces transmission losses.

6 . Better adjustment of line loadings.

\section{2-2 SVC Elements:}

This section presents the different "building blocks" that are commonly used when designing an SVC. The components are presented individually to describe their influence on the grid. We will also briefly discuss some of the problems associated with the components and how these could be handled. This is done to give some insight into how an SVC operates [3]. The different building blocks presented in this section are illustrated in figure .1. 


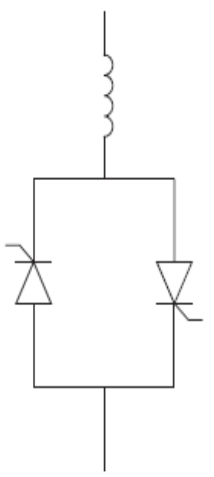

(a) TCR / TSR

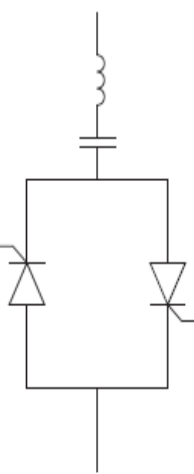

(b) TSC (c) Filter elements.

\section{VOLTAGE STABILITY}

Voltage stability can also be called "load stability". A power system lacks the capability to transfer an infinite amount of electrical power to the loads. The main factor causing voltage instability is the inability of the power system to meet the demands for reactive power in the heavily stressed systems to keep desired voltages. Other factors contributing to voltage stability are the generator reactive power limits, the load characteristics, the characteristics of the reactive power compensation devices and the action of the voltage control devices [10]. Voltage collapse typically occurs in a power system, which is heavily loaded, faulted and/or has reactive power shortages. Voltage collapse is a form of system instability that involves mapower system components and their variables simultaneously. Voltage collapse often involves the entire power system, although it usually has a relatively larger involvement of one particular area of the power system [11].

\section{VOLTAGE STABILITY INDICES}

The purpose of voltage stability indices is to determine the point of voltage instability, the weakest bus in the system and the critical line referred to a bus. These indices are referred to either a bus or a line [12]:

\section{i. P-V Curve}

As the power transfer increases, the voltage at the receiving end decreases. Finally, the critical or nose point is reached. It is the point at which the system reactive power is out of use. The curve between the variation of bus voltages with loading factor $(\lambda)$ is popularly called as P-V curve or 'Nose' curve. PV curves are used to determine the loading margin of the power system. The margin between the voltage collapse point and the current operating point is used as voltage stability criterion [12].

\section{ii. Q-V Curve}

With the help of Q-V curve, it is possible for the operators, to know the maximum reactive power that can be added to the bus before reaching minimum voltage limit. The MVAr distance from the operating point to the bottom of the $\mathrm{Q}-\mathrm{V}$ curve is called as the reactive power margin. Q-V curve can be used as an index for voltage stability limit.

\section{$\mathrm{V} / \mathrm{V}_{\mathbf{0}}$ Index}

The ratio $\mathrm{V} / \mathrm{V}_{\mathrm{o}}$ at each bus shows the voltage stability map of the system. $\mathrm{V}$ is the bus voltage at certain load obtained from load flow study. Voltages $\mathrm{V}_{\mathrm{o}}$ are obtained by solving load flow of the system at an identical state but with all the loads set to zero. This index allows immediate detection of weakest bus and corrective action can be taken to prevent the voltage instability [12].

\section{iii. L-index}

In order to become of practical value the indicator $L$ has to be extended to the multi-node system, there are two categories of nodes which have to be distinguished. One is characterized by the behavior of the PQ-node which stands for a type of consumer node, the other comprise the generator nodes which may be given by a PV-node or by the slack node.

\section{NGS TRANSMISSION LINES-500KV (CASE STUDY)}

NGS transmission lines-500Kv data are presented in table (1) below, where the single line diagram is in figure (2),

Table (1): NGS transmission lines-500Kv

\begin{tabular}{|l|l|l|l|l|}
\hline Name & $\begin{array}{l}\text { Length } \\
\mathrm{km}\end{array}$ & $\begin{array}{l}\mathrm{R}(1) \\
\text { Ohm } / \mathrm{km}\end{array}$ & $\begin{array}{l}\mathrm{X}(1) \\
\text { Ohm/km }\end{array}$ & $\begin{array}{l}\text { C(1)uf/ } \\
\mathrm{km}\end{array}$ \\
\hline $\begin{array}{l}\text { Marwi- } \\
\text { Mrkhit1 }\end{array}$ & 345 & 0.028 & 0.276 & 0.013079 \\
\hline $\begin{array}{l}\text { Marwi- } \\
\text { Mrkhit2 }\end{array}$ & 345 & 0.028 & 0.276 & 0.013079 \\
\hline $\begin{array}{l}\text { Mrkhit1- } \\
\text { Kabashi }\end{array}$ & 36.8 & 0.03 & 0.276 & 1.3083 \\
\hline $\begin{array}{l}\text { Marwi- } \\
\text { Atbra }\end{array}$ & 236.7 & 0.028 & 0.276 & 0.013079 \\
\hline
\end{tabular}

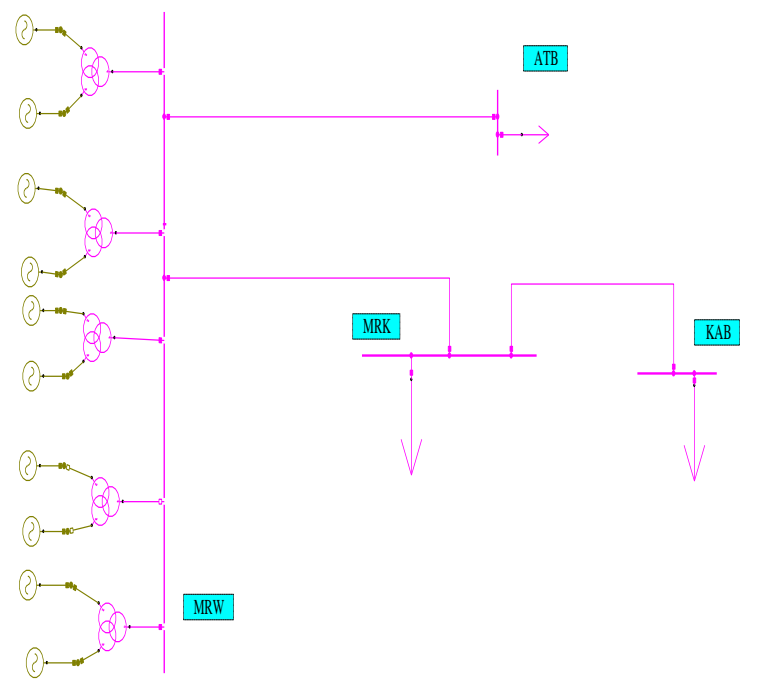

Figure (2): Single line diagram of NGS transmission line 500KV system 


\section{SIMULATION RESULTS}

Simulation for the case study is done using NEPLAN software with loading point $(\lambda)$ equal to 1.2 of the total connected load. The voltage magnitude is calculated without SVC and with it. The results are obtained by installing SVC in two different places (Kabashi busbar and Markhiat busbar) as shown in table 2. The results show SVC can be used to improve voltage magnitude

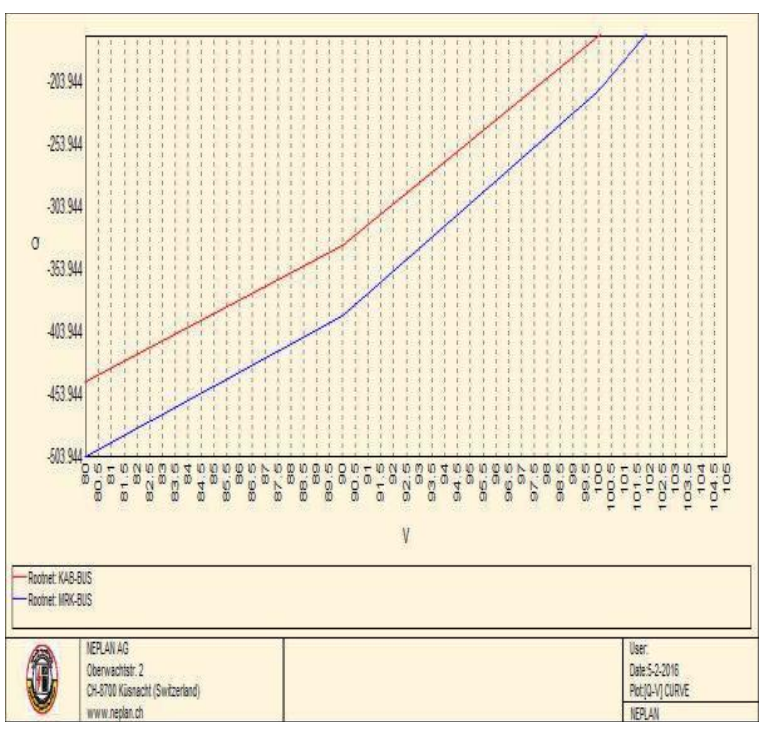

Figure (3) displayed UQ-curve

Figure (3) Show the weakest buses in system, and the esults indicate that the Kabashi busbar has highest Sensitivity because smaller reactive power margin is needed. Thus the Kabashi busbar is the weakest bus and is the bus for optimal location of the reactive power support.

Table (2): Voltage magnitude before \& after installing SVC at kabashi and markhiat busbar

\begin{tabular}{|l|l|l|l|l|}
\hline bus & $\begin{array}{l}\text { V before } \\
\text { Placeme } \\
\text { nt of } \\
\text { SVC }\end{array}$ & $\begin{array}{l}\text { V } \\
\text { after } \\
\text { Placeme } \\
\text { nt of } \\
\text { SVC at } \\
\text { kabashi }\end{array}$ & $\begin{array}{l}\text { V } \\
\text { after } \\
\text { Placement } \\
\text { of SVC at } \\
\text { bus } \\
\text { markhiat }\end{array}$ & $\begin{array}{l}\text { Injecte } \\
\text { d SVC } \\
\text { MVAr }\end{array}$ \\
\cline { 2 - 5 } & $\mathbf{V}_{\mathbf{M}}(\boldsymbol{\%})$ & $\mathbf{V}_{\mathbf{M}}(\boldsymbol{\%})$ & $\mathbf{V}_{\mathbf{M}}(\boldsymbol{\%})$ & \\
\hline marwi & 101 & 103.72 & 103.72 & 0 \\
\hline markhiat & 92 & 98.10 & 98.09 & 91.409 \\
\hline kabashi & 91.16 & 97.54 & 97.15 & 90.392 \\
\hline atbra & 96.1 & 98.97 & 98.97 & 0 \\
\hline
\end{tabular}

The obtained results show the improvement of voltage magnitude, and the best results are obtained when SVC is added to kabashi busbar.

\section{CONCLUSION}

This paper discusses the optimal allocation of SVC to improve the voltage stability. $\mathrm{SVC}_{\mathrm{S}}$ are in general cheaper, higher capacity, faster, and more reliable than dynamic compensation schemes such as synchronous condensers, Voltage profile is improved for the NGS $500 \mathrm{kv}$ transmission lines using SVC. The optimal allocation, is achieved by installing SVC in kabashi busbar with size of 90.392 MVAr.

\section{REFERENCES}

[1] Hadi Saadat," Power system analysis", McGraw-Hill companies, Singapora, 1990.

[2] Ahmed Mustafa Mohammed Mohammed "Improving the Voltage Stability of Electrical Power Systems Using Shunt Facts Devices”, Master thesis, Cairo University November 2009.

[3]. Oscar Skoglund "Dynamic voltage regulation using SVCs, A simulation study on the Swedish national grid", Master thesis, KTH University 2013

[4] RAO, N.GAYATRI, P.BALAJI and K.SINDHU "Modeling and Simulation of Static VAR Compensator Controller for Improvement of Voltage Level in Transmission Lines", International Journal of Electrical and Electronics Research, Vol. 3, Issue 1, pp. (281-288), Month: January - March 2015

[5] C. L. Wadhwa "Electrical Power Systems", Book, Fourth Edition

[6] Nang Sabai, Hnin Nandar Maung, and Thida Win "Voltage Control and Dynamic Performance of Power Transmission System Using Static Var Compensator", World Academy of Science, Engineering and Technology 422008

[7] V. Ganesh, K. Vasu, K. Venkata Rami Reddy, M. Surendranath Reddy and T.GowriManohar "Improvement Of Transient Stability Through SVC", IJAET Nov. 2012

[8] Daniel J. Sullivan "Improvements in Voltage Control and Dynamic Performance of Power Transmission Systems Using Static Var Compensators (SVC)", Master thesis, Pennsylvania State University 1995

[9] Prabha Kundur, "Definition and Classification of Power System Stability", IEEE 2004

[10] Sami Repo "On-line Voltage Stability Assessment of Power System an Approach of Black-box Modelling", Master thesis, Tampere University of Technology 2001

[11] Bishnu Prasad Sapkota "Voltage Stability Assessment and Enhancement of a Large Power System Using Static and Dynamic Approaches", PHD thesis, Arizona State University May 2010

[12] A. R. Phadke, S. K. Bansal and K. R. Niazi "A Comparison of Voltage Stability Indices for Placing Shunt FACTS Controllers", IEEE 2008

[13] Ahmed Salloum "Optimal Location and Sizing of Dynamic VArs for Fast Voltage Collapse", Master thesis, RIZONA STATE UNIVERSITY May 2011.

[14] C. L. Wadhwa "Electrical Power Systems", Book, Fourth Edition

[15] Jan Veleba "Steady State Solution of Electric Power Systems with Accent on Fault Modelling", PHD thesis, Faculty of Electrical Engineering Pilsen, 2013

[16] Popkov, V. I. "Elektroperedacht sverkhvysokogo napriazheniia." In Nauka I chelovechestvo (vol. 6), Moscow, 1967

[17] Sarita Bhole and Prateek Nigam "Improvement of Voltage Stability in Power System by Using SVC and STATCOM”, IJISET 2015 